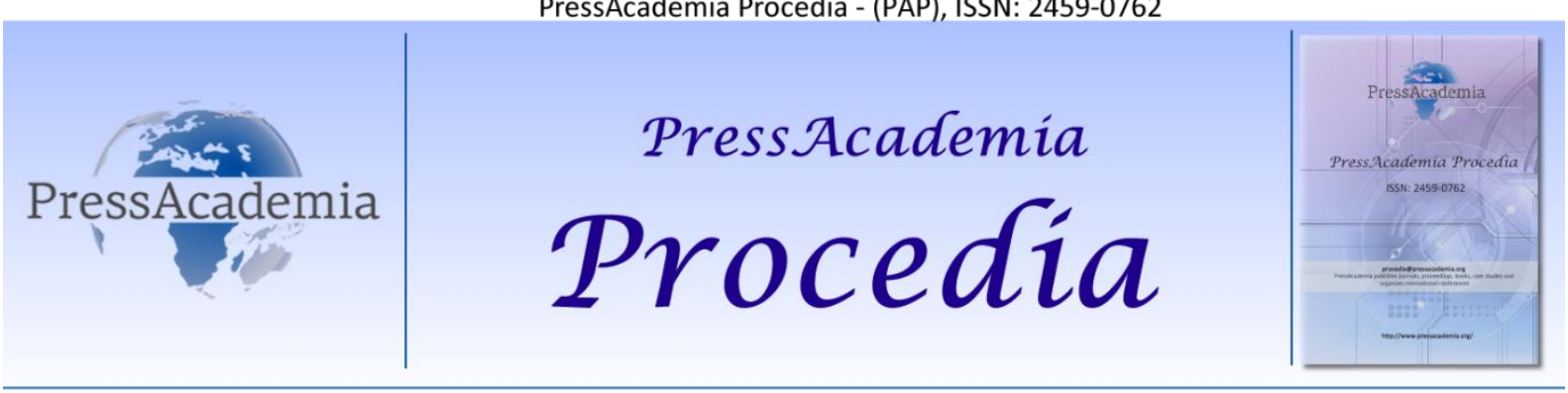

2nd World Conference on Technology, Innovation and Entrepreneurship

May 12-14, 2017, Istanbul, Turkey. Edited by Sefer Şener

\title{
BUDESONIDE SELF-NANOEMULSION FORMULATION AS AN ORAL DRUG DELIVERY SYSTEM: PREPARATION, CHARACTERIZATION AND CYTOTOXICITY STUDIES
}

\author{
DOI: 10.17261/Pressacademia.2017.569 \\ PAP-WCTIE-V.5-2017(7)-p.41-46
}

Burcu Mesut, Seyma Hande Tekarslan Sahin, Yildiz Ozsoy

Istanbul University Faculty of Pharmacy Pharmaceutical Technology Dept., bmesut@istanbul.edu.tr

\begin{abstract}
Lipophilic drugs which are poorly water soluble need specific applications like lipid based delivery systems to increase their oral absorption across gastrointestinal tract. Selfnanoemulsifying drug delivery systems are Lipid Based Drug Delivery systems (SNEEDs) and are consists of an isotropic mixture of oil, surfactant(s) and co-surfactant. This drug delivery systems are prepared at room temperature with gentle stirring process without using any other component or heating process and become nanoemulsion form upon gentle agitation in aqueous phase. SNEDDs have many advantages such as they can be produced easily and they are affected less from other outside factors, its scaleup process is easy, unaffected by lipid digestion, carry and protect peptides which can be enzymatically hydrolyzed. The aim of this study was to increase solubility of Budesonide by using new Snedds formulation approach.
\end{abstract}

Keywords: Budesonide, self-nanoemulsion drug delivery, oral drug delivery, cytotoxicity.

\section{INTRODUCTION}

Budesonide (16,17-butylidenebis(oxy)-11,21-dihydroxypregna-1,4-diene-3,20-dione) is a synthetic glucocorticoid steroid used in the treatment of asthma and an inflammatory bowel disease (Hvizdos and Jarvis, 2000). Molecular weight of Budesonide is $430.5, \log$ P values is 3.2, BCS class II and pratically insoluble in water $(28 \mu \mathrm{g} / \mathrm{mL}$ ) (Ali et al., 2010). It is a potent nonhalogenated corticosteroid and has a relative glucocorticoid receptor affinity of 935 compared with 100 for dexamethasone and a 200-fold higher glucocorticoid receptor affinity and a 1000-fold higher topical anti-inflammatory potency than cortisol.(Ek et al., 1999). Budesonide is completely absorbed from the gastrointestinal tract, however its bioavailability is around $10 \%$ due to hepatic first-pass effect (Meloche et al., 2002). Due to degradation of Budesonide in the liver easily, an alternative way should be developed to avoid the first-pass effect thereby the cellular uptake in the site of action is enhanced (Piao et al., 2009). Approximately $50 \%$ of the drugs in use all over the world are oral medications and the market share continues to increase despite the emergence of new dosage forms (http://www.slideshare.net /jaydeep.adhikari/evolution-of-controlled-release-Technology,http://www.marketsandmarkets.com/Market-eports/northamerican-drug-delivery-technologies-market-1209.html). Oral drug delivery is the most accepted routes because of its patient compliance (Bernkop-Schnürch, 2013). Even though many pharmaceutical compounds have poor water solubility (Amidon et al., 1995), lipid based drug delivery systems (LBDDS) overcome the low bioavailability problem by increasing solubility of this compounds (Pouton, 2000). Self-nanoemulsifying drug delivery systems (SNEEDs) are LBDDS which consist of oil, surfactant and co-surfactant (Bu et al., 2016).

SNEDDs are thermodinamically stable systems. They form emulsion spontaneously when they encounter gastrointestinal fluids, therefore they have fast dispersion process and are less affected by other factors such as food effect during its formation process (Jankovic et al., 2016). After dilution, they create nanoscale size emulsion droplets. Decreasing droplet size increase surface area and improve the dissolution rates as well as bioavailability (Balakumar et al., 2013).

Cell viability assays are used for in vitro toxicity studies. MTT assay is the most used assay for cell viability. MTT (3-[4,5dimethylthiazol-2-yl]-2,5-diphenyltetrazolium bromide) is a tetrazolium salt and is converted to an insoluble purple formazan in viable cells. This conversion is done by succinate dehydrogenase within the mitochondria (Fotakis and Timbrell, 2005). Initial protocol of MTT assay was described by Mossmann (1983). Mitochondrial dehydrogenases in living cells 
reduce MTT into formazon salts which form blue-magenta colour. When cytotoxic compounds damage the cells, MTT can not be reduced by cells and as a result, there is a decrease of the reduction of MTT to formazan (Mueller et al., 2004). The aim of this study was to develop new SNEDD formulation of Budesonide and thus overcoming its first-pass degradation, evaluating specification of this new formulation and performing cytotoxicity studies of budesonide-loaded SNEDD formulation.

\section{MATERIALS AND METHODS}

\subsection{Materials}

Budesonide was kindly donated from Referans Temsilcilik, Turkey. Labrafac Lipophile WL1349, Labrafac PG, Peceol, Pliurol oleique, Transcutol, Labrasol, Labrafil M2125 was gifted from Gatteffosse. RPMI 1640 medium, 0.05\% trypsin-EDTA solution, DPBS without Calcium, Magnesium and phenol red, Fetal bovine serum (FBS), were purchased from PAN-Biotech (Germany). Penicillin-Streptomycin $(10,000 \mathrm{U} / \mathrm{mL})$ were obtained from Gibco (USA). 3-(4,5-dimethyl-thiazol-2-yl)-2,5diphenyl-tetrazolium bromide (MTT) were obtained from Sigma. All other chemicals were of analytical grade.

\subsection{Methods}

\subsubsection{Preparation of SNEDDs Formulations}

Self-nanoemulsions were prepared by mixing of oil phase; Labrafac Lipophile WL1349, Labrafac PG and Peceol, surfactant; Labrasol ${ }^{\circledR}$ and Gelucire $48 / 16^{\circledR}$ and co-surfactant; Transcutol ${ }^{\circledR}$. Ternary phase diagrams of surfactants, co-surfactants and oils were constructed to recognize the zone of nanoemulsion formation. Samples were prepared and for each sample oil and surfactant(s): co-surfactant ratio were mixed in ratios ranging from \%10:90 - \%90:10 like 1:9, 2:8, 3:7, 4:6, 5:5, 6:4, 7:3, $8: 2$ and 1:9. Once the self-emulsifying region was identified, the desired component ratios of SNEDDS were selected.

\subsubsection{Analytical Method}

Budesonide is an epimeric mixture of two isomers. USP Method was modified to quantitate budesonide in formulations. The HPLC system utilized consists of a LC-20AD liquid chromatography equipped with 20A DAD detector. Chromatographic separations were performed on C18 $(4.6 \times 250 \mathrm{~mm}, \mathrm{~L} 1 ; 5 \mu \mathrm{m}$ packing) which was attached with loop $100 \mu \mathrm{L}$.Mobile phase of acetonitril: Buffer solution ( $\mathrm{pH}$ 3.2) (32:68 (V/V)) was used. Buffer solutions were filtered through filtration unit (Millipore, $0.45 \mu \mathrm{m}$ pore size) and degassed before use. The flow rate was maintained at $1.5 \mathrm{~mL} / \mathrm{min}$ and injection volume was $50 \mu \mathrm{L}$. Detection was performed at a wavelength of $254 \mathrm{~nm}$ and analysis was carried out at ambient temperature.

\subsubsection{Solubility Studies in Excipients}

Determination of drug solubility of Budesonide an excess amount active pharmaceutical ingredient (API) in various oils, surfactants and co-surfactants were carried out by adding an excess amount of API in to $1 \mathrm{ml}$ of the vehicle. The mixture was shaken in an orbital shaker $\left(25 \pm 1{ }^{\circ} \mathrm{C}\right)$ (Thermo, USA) for $24 \mathrm{~h}$. The equilibrated mixture was centrifuged at $15000 \mathrm{rpm}$ for $15 \mathrm{~min}$ and excess insoluble budesonide was removed by filtration. The filtrate was analyzed for the amount of budesonide RP-HPLC (Shimadzu, Japan) at $254 \mathrm{~nm}$.

\subsubsection{Solubility Studies at Different pHs}

Budesonide solubility at different $\mathrm{pH}$ were analyzed. The Buffer solutions were prepared at three deifferent $\mathrm{pH}(1.2,4.5 \mathrm{ve}$ 7.4) to determine solubility of budesonide at physiologyc $\mathrm{pH}$ values. An excess amount of budesonide were added in $1 \mathrm{~mL}$ buffer solutions. The mixture was shaken at $25 \pm 1{ }^{\circ} \mathrm{C}$ in an orbital shaker (Thermo, USA) for $24 \mathrm{~h}$. The equilibrated mixture was centrifuged at $15000 \mathrm{rpm}$ for $15 \mathrm{~min}$ and excess insoluble budesonide was removed by filtration. The filtrate was analyzed.

\subsubsection{Physicochemical Properties}

The $\mathrm{pH}$ value of Snedds formulations were analysed at $25{ }^{\circ} \mathrm{C}$ temperature by using Inolab pHmeter. Droplet size and polidispersity index values were measured by Zetasizer after diluting in purified water and buffer solutions at different physiological pHs at $25^{\circ} \mathrm{C}$ and $37^{\circ} \mathrm{C}$.

\subsubsection{Drug Loading Capacity of Chosen Formulations}

The solubility of budesonide in formulations was determined. The same procedure was applied as excipients solubility studies. 


\subsubsection{Cell Culture}

The Human Colorectal Adenocarcinoma Caco-2 was cultured in RPMI1640 supplemented with 10\% FBS and 100 units $/ \mathrm{mL}$ penicillin-Streptomycin. Cells were cultured at $37^{\circ} \mathrm{C}$ in a humidified atmosphere of $5 \% \mathrm{CO}_{2}$. Medium was removed third times a week. Confluent cells were removed from cell culture dishes with $0.25 \%$ sterile trypsin.

\subsubsection{Cell Viability Assay}

MTT (3-[4,5-dimethylthiazol-2-yl]-2,5 diphenyltetrazolium bromide) assay was used to determine cell viability. Caco-2 cells ( $2 \times 104$ cells/well) were cultured in 96 well plate at $37^{\circ} \mathrm{C}$ in a humidified atmosphere of $5 \% \mathrm{CO} 2$. After cells were grown for 24 hours, budesonide loaded SNEDDS were applied to wells at concentration of $0.05,0.10,0.25$, and $0.50 \%(\mathrm{v} / \mathrm{v})$ for $2 \mathrm{~h}$ and $24 \mathrm{~h}$. Cells treated with medium only is used as control group. After treatment with SNEDDS, the supernatant was discarded and MTT solution ( $5 \mathrm{mg} / \mathrm{ml}$ in PBS) and medium were introduced to wells. After incubation with MTT solution, MTT solution was replaced with DMSO to dissolve the formazan crystals. The optical density (OD) of the wells was determined using a plate reader (Thermoscientific Multiskan Ex, USA) at a test wavelength of $570 \mathrm{~nm}$ and a reference wavelength of $630 \mathrm{~nm}$. All experiments were performed in triplicate, and the relative cell viability (\%) was expressed as the absorbance ratio between budesonide-loaded SNEDDS treated and untreated control cells.

\section{RESULTS and DISCUSSIONS}

Phase diagram studies help to understand phase behavior of the formed nanoemulsion (Balakumar et al., 2013). Diagrams were constructed to determine the self-nanoemulsifying area and to make a decision about an optimum concentration of oil, surfactant and co-surfactant for the development of liquid SNEDDS formulations. An example of phase diagram studies was given in Figure 1.

Figure 1: A Sample of Phase Diagram Study (oil: Peceol, surfactant/Co-surfactant: Labrasol-Transcutol 1:1)

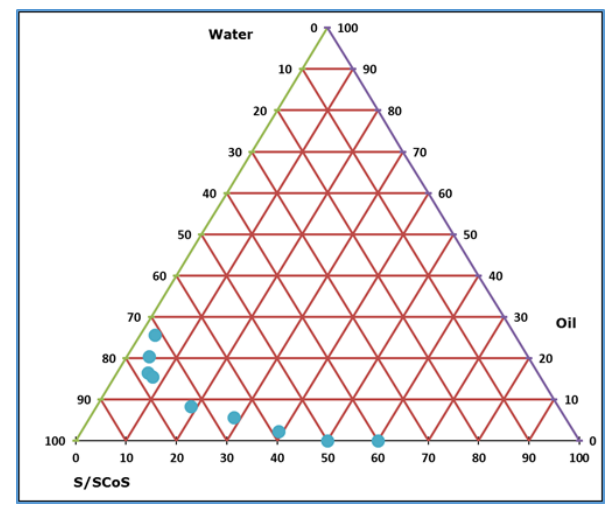

Solubility studies in excipients play important role to determine SNEDD formulation stablities and to prevent in situ precipitaion previously (Parmar et al., 2011).

Figure 2: Drug Solubility Results in Excipients

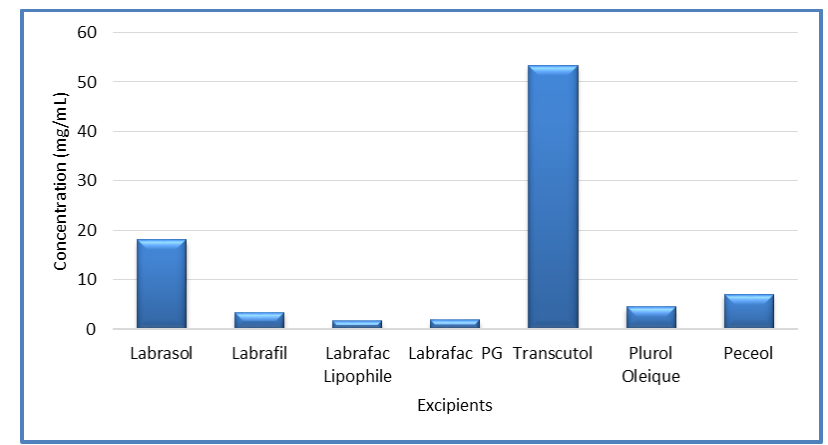


Figure 3: Drug Solubility Results at Different pH Values

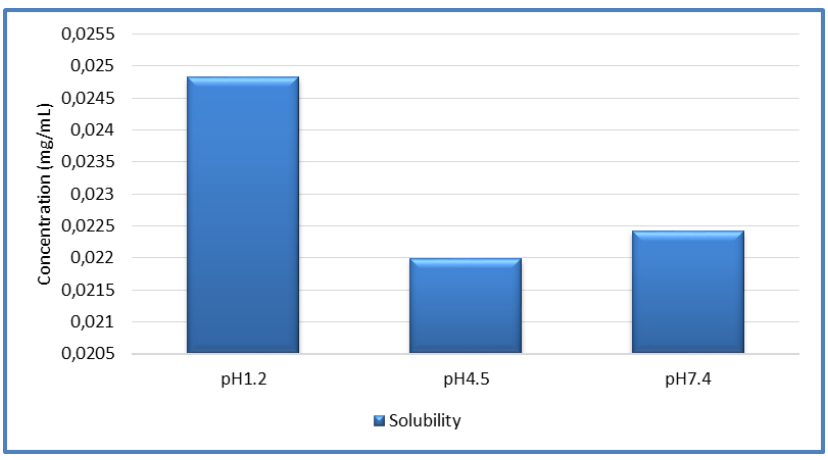

Figure 4: Drug Loading Capacity of Thechosen Formulations

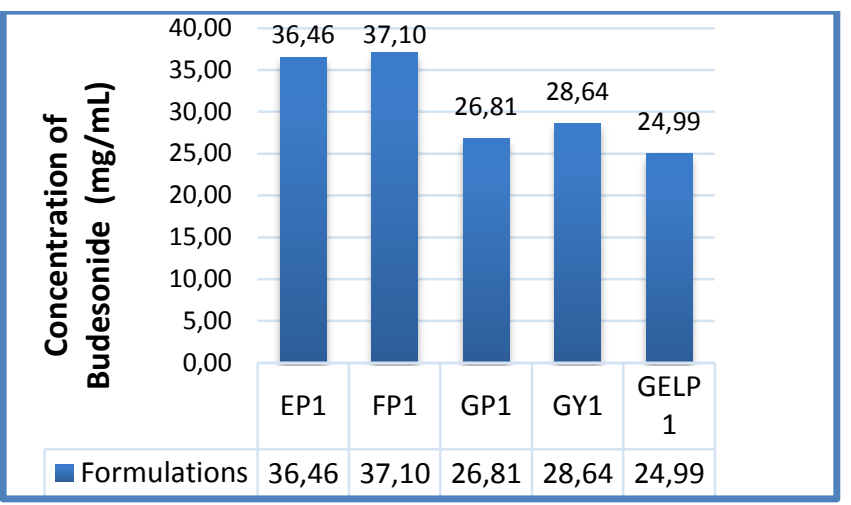

The obtained mixture of the formulation should be clear, monobasic at the room temperature and isotropic (Qi et al., 2011). Nanoemulsion Droplet size is an important characteristics to evaluate formulation stability and a critical criterion of enhancing drug bioavailability (Xi et al., 2009). The droplet size of $1 \%$ solution of SNEDD in the different buffer solution pHs were approximatly $18 \mathrm{~nm}$ and PDI values are below then 0.3. This results show us how SNEDD formulation is stable even at different $\mathrm{pH}$ values and that means SNEDD globules are not affected at different physiological fluids (See Table 1).

Table 1: Droplet Size (nm) of 1\% Solution in Different pH Buffer Solutions

\begin{tabular}{|l|c|c|c|c|c|c|c|c|}
\cline { 2 - 9 } & \multicolumn{2}{|c|}{$\mathbf{p H ~ 1 . 2}$} & \multicolumn{2}{c|}{$\mathbf{p H ~ 4 . 5}$} & \multicolumn{2}{c|}{$\mathbf{p H ~ 6 . 8}$} & \multicolumn{2}{c|}{$\mathbf{p H ~ 7 . 4}$} \\
\cline { 2 - 9 } & $\mathbf{2 5 ^ { \circ }} \mathbf{C}$ & $\mathbf{3 7}^{\circ} \mathbf{C}$ & $\mathbf{2 5}^{\circ} \mathbf{C}$ & $\mathbf{3 7}^{\circ} \mathbf{C}$ & $\mathbf{2 5}^{\circ} \mathbf{C}$ & $\mathbf{3 7}^{\circ} \mathbf{C}$ & $\mathbf{2 5}^{\circ} \mathbf{C}$ & $\mathbf{3 7}^{\circ} \mathbf{C}$ \\
\hline Size $_{\text {average }}(\mathrm{nm})$ & 16,78 & 17,24 & 19,22 & 19,73 & 17,37 & 17,95 & 18,01 & 18,56 \\
\hline PDI $_{\text {average }}$ & 0,238 & 0,273 & 0,062 & 0,115 & 0,135 & 0,153 & 0,268 & 0,286 \\
\hline
\end{tabular}

The change in droplet size after 24 hours in $1 \%$ pH 6.8 buffer solution was investigated. There was no change in droplet size after 24 hours. Test results were given at Table 2.

Table 2: Droplet Size (nm) of 1\% Solution at pH 6.8 after $24 \mathrm{~h}$.

\begin{tabular}{|l|c|c|}
\cline { 2 - 3 } \multicolumn{1}{c|}{} & \multicolumn{2}{c|}{ pH 6.8} \\
\cline { 2 - 3 } \multicolumn{1}{c|}{} & $25^{\circ} \mathrm{C}$ & $37^{\circ} \mathrm{C}$ \\
\hline Size $_{\text {average }}(\mathrm{nm})$ & 17.17 & 17.86 \\
\hline $\mathrm{PDI}_{\text {average }}$ & 0.128 & 0.167 \\
\hline
\end{tabular}


MTT assay was carried out to determine suitable concentration for SNEDDS formulation. Caco-2 cells were exposed to budesonide-loaded SNEDDS for 2 and $24 \mathrm{~h}$. MTT assay test of this formulation showed that toxicity of formulations were concentration-dependent. The empty SNEDDS formulation and budesonide-loaded formulation have significantly higher viability at a concentration of $0.05(\mathrm{v} / \mathrm{v})$ compared to the other concentrations $(0.10,0.25$, and $0.50 \%(\mathrm{v} / \mathrm{v}))$. Cytotoxicity is not observed in SNEDDS at concentration of $0.05(\mathrm{v} / \mathrm{v})$. Loss of cell viability was obvious at concentration of $0.10(\mathrm{v} / \mathrm{v})$. While there is no difference between $2 \mathrm{~h}$ and $24 \mathrm{~h}$ for survival ratios at concentration of $0.05(\mathrm{v} / \mathrm{v})$, increase of the concentration decreases survival ratios. As the concentration of SNEDD formulation gets higher $(0.25(\mathrm{v} / \mathrm{v})$ and $0.50 \%(\mathrm{v} / \mathrm{v}))$, administration of the SNEDD formulation for $24 \mathrm{~h}$ becomes more toxic compared to $2 \mathrm{~h}$. These results showed that the cell viability was decreased as a function of time at concentration of $(0.25(\mathrm{v} / \mathrm{v})$ and $0.50 \%(\mathrm{v} / \mathrm{v}))$. Budesonide loaded SNEDD and empty SNEDD at concentration of $0.05(\mathrm{v} / \mathrm{v})$ can be regarded as non-toxic for Caco-2 cells during the incubation time. SNEDDS at concentration of $0.25(\mathrm{v} / \mathrm{v})$ and $0.50 \%(\mathrm{v} / \mathrm{v})$ result in a significant lower viability in Caco-2 cells due to containing higher concentration of Peceol which is a surfactant.

Figure 5: Cell Viability for Caco-2 Cells Following Exposure to SNEDDS as Derived from MTT Assay ( $n=3$ ).

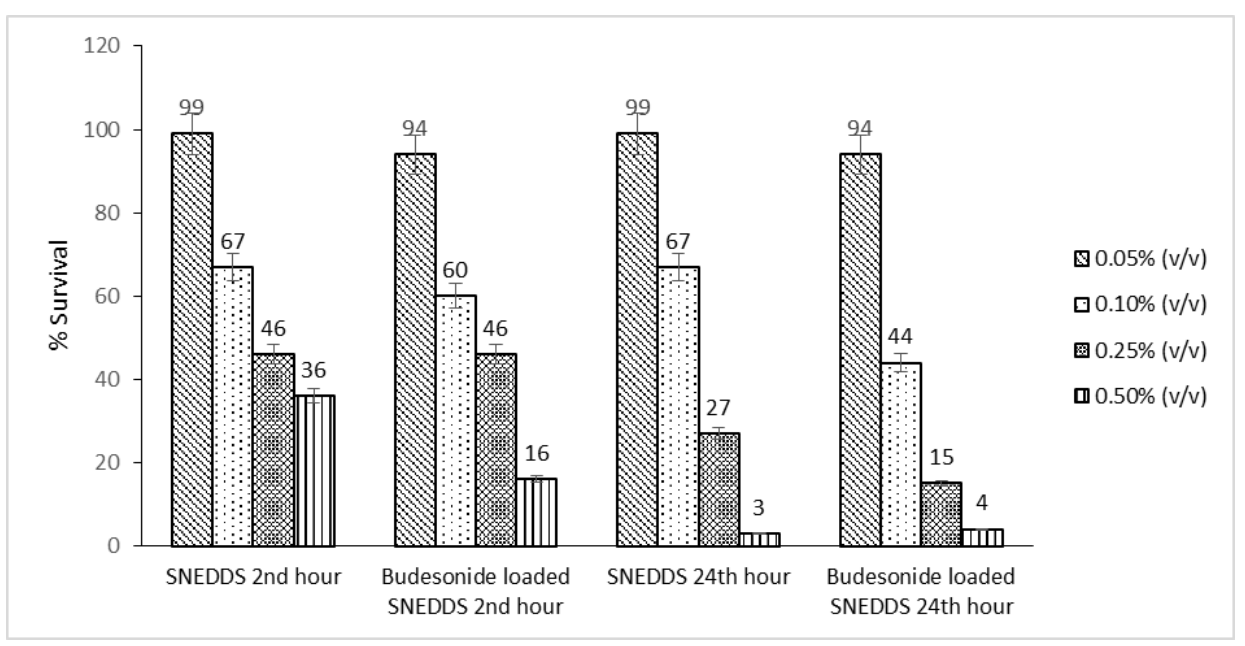

\section{CONCLUSION}

Each formulation was evaluated based on their physicochemical characteristic and formulations which contain Peceol as oil phase, Labrasol and Gelucire 48/16 as surfactants and Transcutol as co-surfactant were chosen. To have an idea about the fate of the formulation in GIT, in vitro release studies will be performed.

This is the first study, to our knowledge, budesonide loaded SNEDDS were produced and characterized. Budesonide-loaded formulation $(0.05,0.10 \%(\mathrm{v} / \mathrm{v}))$ exhibited low toxicity. It demonstrated that this formulation at concentrations of $0.05 \%$, $0.10 \%(\mathrm{v} / \mathrm{v})$ are convenient for oral administration.

\section{ACKNOWLEDGMENT}

This study supported by Istanbul University BAP no: 47691.

\section{REFERENCES}

Ali, H. S., York, P., Blagden, N., Soltanpour, S., Acree Jr., W. E., Jouyban, A. 2010. "Solubility of budesonide, hydrocortisone, and prednisolone in ethanol + water mixtures at $298.2 \mathrm{~K}$," , Journal of Chemical and Engineering Data, vol. 55(1), pp. 578-582.

Amidon, G.L., Lennernäs, H., Shah, V.P., Crison, J.R. 1995. "A theoretical basis for a biopharmaceutic drug classification: the correlation of in vitro drug product dissolution and in vivo bioavailability", Pharmaceutical Research, vol. 12, pp. 413-420.

Balakumar, K., Raghavan, C.V., Selvan, N.T., Prasad, R.H., Abdu, S. 2013. "Self nanoemulsifying drug delivery system (SNEDDS) of Rosuvastatin calcium: Design, formulation, bioavailability and pharmacokinetic evaluation". Colloids and Surfaces B: Biointerfaces, vol. 112, pp. 337-343.

Bernkop-Schnürch, A. 2013, “Nanocarrier systems for oral drug delivery: Dowereally need them?". European Journal of Pharmaceutical Sciences, vol. 49, pp. 272-277. 
Bua, P., Narayanana, S., Dalrymplec, D., Chenga, X., Serajuddin A.T.M. 2016, "Cytotoxicity assessment of lipid-based self-emulsifying drug delivery system with Caco-2 cell model: Cremophor EL as the surfactant", European Journal of Pharmaceutical Sciences, vol. 91, pp. 162171.

Ek, A., Larsson, K., Siljerud, S., Palmberg, L. 1999. "Fluticasone and budesonide inhibit cytokine release in human lung epithelial cells and alveolar macrophages", Allergy, vol. 54, pp. 691-699.

Fotakis, G., Timbrell, J.A. 2006. "In vitro cytotoxicity assays: comparison of LDH, neutral red, MTT and protein assay in hepatoma cell lines following exposure to cadmium chloride", Toxicol Lett., vol. 160(2), pp. 171-177.

http://www.marketsandmarkets.com/Market-Reports/north-american-drug-delivery-technologies-market-1209.html, Accessed on 17.03.2017

http://www.marketsandmarkets.com/Market-Reports/north-american-drug-delivery-technologies-market-1209.html, Accessed on 17.03.2017

Hvizdos, K.M., Jarvis, B, 2000. "Budesonide inhalation suspension: a review of its inflammatory respiratory disorders", Drugs, vol. 60 (5), pp.1141-1178.

Janković, J., Djekic, L., Dobričićc, V., Primoracb. 2016. "Evaluation of critical formulation parameters in design and differentiation of selfmicroemulsifying drug delivery systems (SMEDDSs) for oral delivery of acyclovir", International Journal of Pharmacy, vol. 497(1-2), pp. 301-311.

Meloche, C.A., Sharma, V., Swedmark, S., Andersson, P., Falany, C.N. 2002. "Sulfation of budesonide by human cytosolic sulfotransferase, dehydroepiandrosteronesulfotransferase (DHEA-ST)", Drug Metabolism \& Disposition, vol. 30, pp. 582-585.

Mosmann T. 1983. "Rapid colorimetric assay for cellular growth and survival: application to proliferation and cytotoxicity assays". Journal of Immunologyc Methods, vol. 65(1-2), pp. 55-63.

Mueller, H., Kassack, M.U., Wiese, M. 2004. "Comparison of the usefulness of the MTT, ATP, and calcein assays to predict the potency of cytotoxic agents in various human cancer cell lines". Journal of Biomolecular Screening, vol. 9(6), pp. 506-515.

Parmar, N., Singla, N., Amin, S., Kohli, K. 2011. "Study of cosurfactant effect on nanoemulsifying area and development of lercanidipine loaded (SNEDDS) self nanoemulsifying drug delivery system". Colloids Surface. B: Biointerfaces, vol. 86, pp. 327-338.

Piao, H.-M., Cho, H.-J., Oh, E.-C., Chung, S.-J., Shim, .C.-K., Kim, D.-D. 2009. "Budesonide Microemulsions for Enhancing Solubility and Dissolution Rate", Journal of Korea Pharmaceutical Sciences, vol. 39 (6), pp. 417-422.

Pouton C.W. 2000, "Lipid formulations for oral administration of drugs: non-emulsifying, self-emulsifying and 'self-microemulsifying' drug delivery systems", European Journal of Pharmaceutical Science, vol. 11, pp. 93-98.

Xi, J., Chang, Q., Chan, C.K., Meng, Z.Y., Wang, G.N., Sun, J.B., Wang, Y.T., Tong, H.H., Zheng, Y. 2009 "Formulation development and bioavailability evaluation of a self-nanoemulsified drug delivery system of oleanolic acid”. AAPS PharmSciTech, vol. 10, pp. 172-182.

USP 31, http://www.usp.org/sites/default/files/usp_pdf/EN/USPNF/revisions/m10458budesonide.pdf, Accesed on 20.03.2017

Qi, X., Wang, L., Zhu, J., Hu, Z., Zhang, J. 2011 "Self-double-emulsifying drug delivery system (SDEDDS): a new way for oral delivery of drugs with high solubility and low permeability" International Journal of Pharmacy, vol. 409, pp. 245-251. 